\title{
Artificial InTELligenCE IN MANUFACTURING COMPANIES AND BROADER: AN OVERVIEW
}

\author{
Buchmeister, B., PAlCiC, I. \& OJSTERSEK, R.
}

Abstract: The workplace as we know it and production systems as a whole will not be recognizable in a decade's time. In this chapter an overview of expected future changes in manufacturing systems is given. Artificial intelligence (AI) is the key driver in this change and it is critical to prepare us for a future dominated by AI. Robots and AI will prove far more disruptive than anything we have seen before. The most effective AI systems will be designed around the concept of intelligent augmentation. They will handle the math and basic analysis, relieving skilled operators of a tedious burden, absorb data, classify and prioritize information, conduct simulations and ultimately leave it to the human operator to decide the course of action. In the AI future, jobs requiring human creativity and management expertise will enjoy the greatest job security. This is our competitive advantage as humans. Those who understand the collaboration with other humans while working with AI tools to enhance their organization's effectiveness will create maximum value. An energy-and resourcefriendly production is an important key performance indicator for industrial companies to work economically and remain competitive.

Key words: Intelligent manufacturing, Artificial intelligence, Robots, Sustainability, Jobs
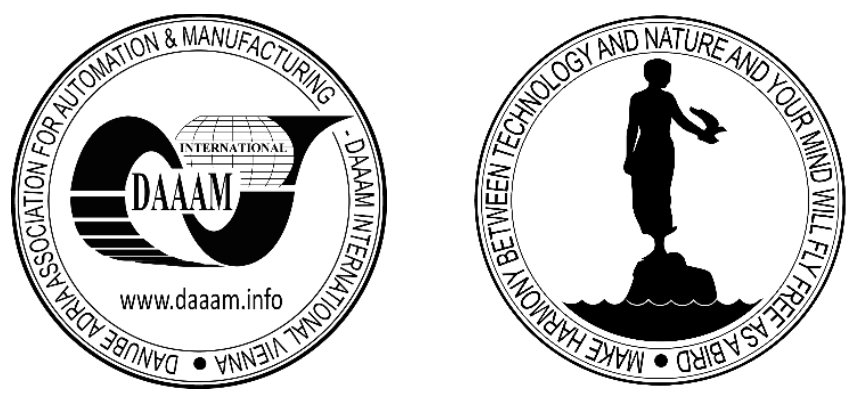

Authors' data: Prof. Dr. Sc. Buchmeister, B[orut]; Assoc. Prof. Dr. Sc. Palcic, I[ztok]; M. Sc. Ojstersek, R[obert], University of Maribor, Faculty of Mechanical Engineering, Laboratory for Production Management, Smetanova 17, 2000 Maribor, Slovenia, borut.buchmeister@um.si, iztok.palcic@um.si, robert.ojstersek@um.si

This Publication has to be referred as: Buchmeister, B[orut]; Palcic, I[ztok] \& Ojstersek, R[obert] (2019). Artificial Intelligence in Manufacturing Companies and Broader: An Overview, Chapter 07 in DAAAM International Scientific Book 2019, pp.081-098, B. Katalinic (Ed.), Published by DAAAM International, ISBN 978-3902734-24-2, ISSN 1726-9687, Vienna, Austria

DOI: $10.2507 /$ daaam.scibook.2019.07 


\section{Introduction}

The development of Artificial Intelligence (AI) is one to the most important events in recent human history. Human activity has long become the most defining influence on our global ecosystem. The pace of change has rapidly accelerated in the last 250 years since the invention of the steam engine and the resulting first industrial revolution.

Now, we are at the brink of a new revolution, which is driven by the transformative power of emerging technologies. Technologies like Artificial Intelligence, genetic engineering, virtual reality, robotics, and 3D printing will fundamentally change our lives in the future. They are incomparably more powerful and develop at a much faster pace than any technology before.

Over the last few hundred years, technology and innovation have led to a vast improvement of our living conditions. While surely, technology is also among the culprits of many of our problems, it is clear that technological development and innovation will be at the heart of moving towards a sustainable future.

The possibilities of machine or artificial intelligence were already recognized and discussed in the mid-1940s by Turing. Technology enthusiast and AI researcher Tegmark (2017) talks about the opportunities of AI and is convinced we can grow the world's prosperity through automation, without leaving people lacking income or purpose; according to Tegmark, when AI is utilized in this manner, humanity does not have to fear an arms race. Rather than worry about an unlikely existential threat, the consideration of how AI will enhance human life is needed. Intelligent machines can fail in ways that are different from human error patterns, ways we do not expect or are prepared for and that call for holding on ever tighter to human values and ethics. Important questions address the relation between AI and sustainability, as well as sustainable development, in terms of a technology impact assessment.

In our study (related and limited with existent reports), we provide an overview of the major future changes in the production branch (and more broadly in the social sense) triggered by the use of artificial intelligence. We also discuss the critical points, opportunities and threats that new technologies and anticipated changes can cause.

\section{AI Tools - Technology}

AI can play an important role in forwarding sustainable development. The hopes are based on the application of some key capabilities within the domain of AI. These are capabilities in the area of Natural Language Processing, like Speech Recognition, or Machine Translation; or in Computer Vision, with Image Recognition and Classification.

AI has been a constant theme in computing research and many researchers, including Turing, have conducted research on AI. The study of Artificial Intelligence began back in 1956 when a group of researchers got together in New Hampshire to discuss how machines could perform "intelligent actions". Since then the landscape has gradually evolved, thanks to technological changes such as increased computational power and new discoveries in neuroscience (Silva, 2018). With over 60 
years of research, much progress has been made in AI, and especially, different types of AI are accelerating together with their related technologies. Not to mention, the invention of intelligent machines have further accelerated the development of AI (Müller, 2014).

How then should we describe AI today? AI refers to "any computer system able to perform tasks that generally require human intelligence", according to the dictionary. How is that possible in practice? AI capabilities today derive from three major sources:

- First, data - the huge amount of information provided by the Internet of Things.

- Second, perception - that is, the ability to recognise voice and images.

- Third, cognition and problem solving - that is, the ability to continuously learn and improve.

AI is a pervasive technology, the application and impact of which span all sectors of the economy, from manufacturing and media to education to healthcare. The four types of intelligences are as follows (Huang \& Rust, 2018):

- mechanics (minimal degree of learning or adaption),

- analytical (learns and adapts systematically based on data),

- intuitive (learns and adapts intuitively based on understanding),

- empathetic (learns and adapts empathetically based on experience).

The activities may include creativity, the ability to understand spoken language, rational inference, and making judgments based on insufficient and conflicting data as well as previous experiences. Such activities may have both benefits and disadvantages in today's society. Pavaloiu and Kose (2017) suggest that outsourcing ethics is impossible in AI, even though there is algorithmic responsibility since every other system, cannot always perform the right things in the correct manner and for the proper reasons. Systems such as robots are unreliable and cannot be fully trusted due to their unreliability. Fear exists in our minds of these robots doing the right thing, becoming autonomous, and rebelling against humans one day. Ethical laws must be considered when designing and deploying robots.

Most of the recent advances in AI are based on the application of different machine learning techniques. Deep-learning AI is becoming ever more capable. Using such algorithms, computers are equipped with the ability to learn without being explicitly programmed. You need a suitable set of training data, and you need sufficient computational resources to do the training. Such systems are ideal for classification tasks, but the person using AI algorithms of this sort is in the dark about how the system actually makes its decisions.

A general, deep-learning AI routine could, some time from now, be trained with a company's data, automatically run simulations of the feasible futures and create algorithms needed to deliver the desired business efficiencies. The AI might use already known operations research algorithms, apply them to new situations and constantly adjust and recalculate to maintain optimal efficiency. It could develop algorithms to optimize the shipment of consumer products for a single device manufacturer, identifying the most efficient way to deliver each item from the factory to the store shelf or the consumer's doorstep. It would gradually expand capabilities to 
ensure an optimized delivery of the raw materials needed to produce the devices and every other logistical task needed to cut costs and boost factory productivity. This AI application might then optimize marketing efforts, ensuring the product design meets customer expectations, as well as ensuring that advertising accurately targets those most interested in the product. It might adapt to help retailers in optimizing product placement on store shelves, and then provide support for logistics, marketing, accounting and all the other common business tasks (Byrum, 2018).

AI's negative side: AI looks like incredibly promising technology. It is inspiring and exciting but that is probably also, what makes it partially terrifying. There is still too much vagueness around it. A fair and varied amount of criticism has been raised in relation to what extent $\mathrm{AI}$ can be used to promote development, touching upon the human elements that a machine lacks such as the ability to understand ethical and philosophical questions. AI can compute, but cannot judge, as it inevitably lacks crucial human qualities such as wisdom, empathy, compassion and so on. Without a political and societal environment to support its development, AI alone certainly cannot foster sustainable transformation.

The type of AI we are dealing with today is known as "narrow" AI. This is different to the much referenced "strong" AI which is thought to mimic the general human consciousness. Each of these existing systems can be brilliant in specifically defined, constrained tasks, where they can deal with uncertainty better than humans do. In the real industrial world, nothing is ever fully known (Zavalishina, 2017).

AI can bring some daunting impressions. Widespread job losses and apocalyptic scenarios of super intelligence confronting mankind are just two of topics that the media like to focus on. The ethical responsibility around algorithmic decisions tends to command much attention but mostly overlooking the benefits of AI.

As data processing and storage costs drop, and computing power and algorithms become readily available, AI occupies unique spot. It cannot only bring tangible business returns in a very short term but also positively impacts energy consumption, and related environmental aspects in global production.

By 2020, there will be 30 billion connected devices on earth. This is leading to the Big Data mountain growing beyond recognition. Machines communicating with people and other machines are creating so much data that we have generated more in the past two years than in the previous 5,000 years of human history (Hall, 2017).

There is no doubt that the manufacturing sector is leading the way in the application of AI technology. From significant cuts in unplanned downtime to better designed products, manufacturers are applying AI-powered analytics to data to improve efficiency, product quality and the safety of employees (Kushmaro, 2018).

AI algorithms formulate estimations of market demands by looking for patterns linking location, socioeconomic and macroeconomic factors, weather patterns, political status, consumer behaviour and more. This information is invaluable to manufacturers as it allows them to optimize staffing, inventory control, energy consumption and the supply of raw materials.

AI technology is now making its way into manufacturing, and the machinelearning technology and pattern-recognition software at its core could hold the key to transforming factories of the near future. 
There is also no question that AI holds the key to future growth and success in manufacturing. In a recent Forbes Insights survey on artificial intelligence, $44 \%$ of respondents from the automotive and manufacturing sectors classified AI as "highly important" to the manufacturing function in the next five years, while $49 \%$ said it was "absolutely critical to success" (Forbes, 2018).

AI in manufacturing promises massive leaps forward in productivity, environmental friendliness and quality of life, but research shows that while $58 \%$ of manufacturers are actively interested, only $12 \%$ are implementing it (Puittinen, 2018).

\section{Industrial Sector, Manufacturing}

The industrial sector is responsible for one third of the world's GDP and half of the world's energy consumption. It is a major user of freshwater and other natural resources, as well as a mass generator of waste and emissions. With such a large impact on the environment, the efficiency improvements of industrial processes are pivotal to the world's sustainable future (Zavalishina, 2017).

There is a tremendous opportunity for manufacturers. However, it can only be realised by using emerging information technologies like social, mobile, analytics, and cloud alongside operational technologies like sensors, machine-to-machine communication, additive manufacturing, and robotics.

Much of the emphasis has been put on the replacement of the old technologies with new renewable energy sources and a variety of "green" production initiatives. It is inconceivable to think that these could be implemented short term across the world. Particularly when you consider that, the heavy industries - that contribute most to the waste and resource consumption - operate in a slim-margin sector that is struggling to remain competitive. Instead, businesses are focusing on their survival rather than investments into a sustainable future.

For manufacturers, growth in an Industry 4.0 environment will be intrinsically linked with a business's ERP system. Certainly, the boundaries between production and management must disappear, and ERP and manufacturing execution systems (MES) must form an integrated unit if businesses are to realise the growth opportunities presented by this new age of intelligent manufacturing (Fig. 1), involves intelligent products, intelligent manufacturing processes, and intelligent services.

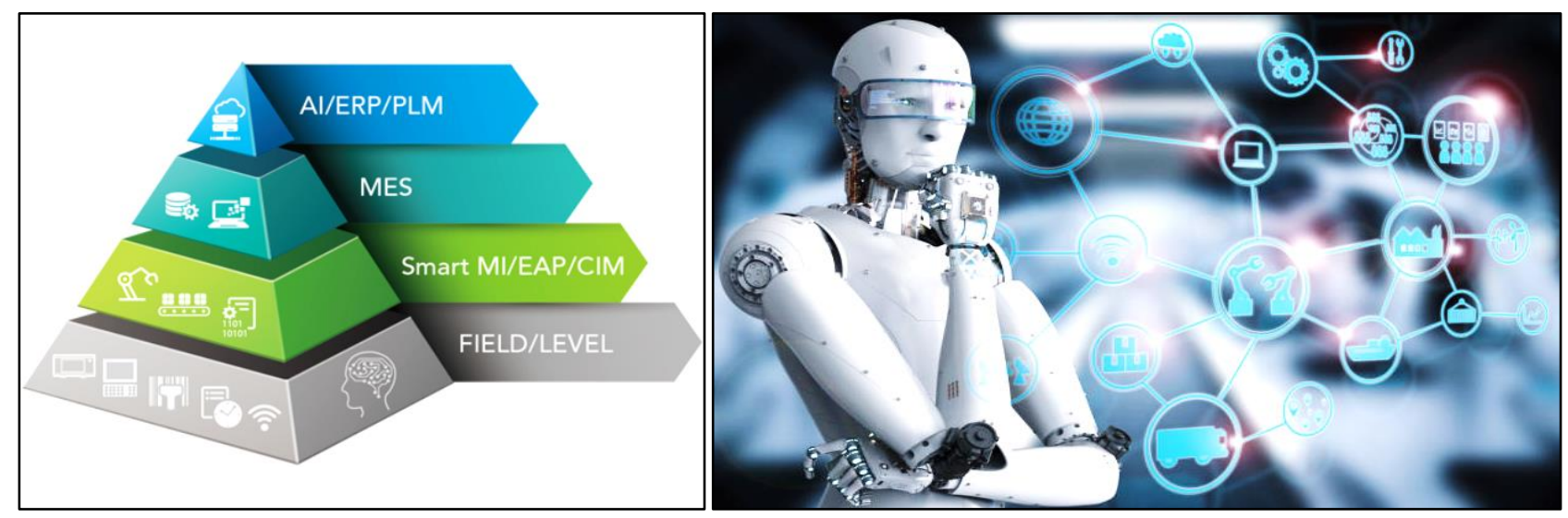

Fig. 1. AI solutions are revolutionizing manufacturing (Kushmaro, 2018). 
Buchmeister, B.; Palcic, I. \& Ojstersek, R.: Artificial Intelligence in Manufacturing...

Intelligent manufacturing is a constantly evolving concept, which can be summarized into three basic paradigms: digital manufacturing $\left(1^{\text {st }}\right.$ generation intelligent manufacturing), digital-networked manufacturing ( $2^{\text {nd }}$ generation$)$, and new-generation intelligent manufacturing (Zhou et al., 2018). By analysing the evolution of intelligent manufacturing, it is evident, that the process of developing from traditional manufacturing to intelligent manufacturing is also a process of developing from the original human-physical systems (HPS) to human-cyber-physical systems (HCPS). An HCPS reveals the basic principles of intelligent manufacturing development and is the theoretical basis for supporting the development of newgeneration intelligent manufacturing, which is shown in Fig. 2 (Wang et al., 2018).

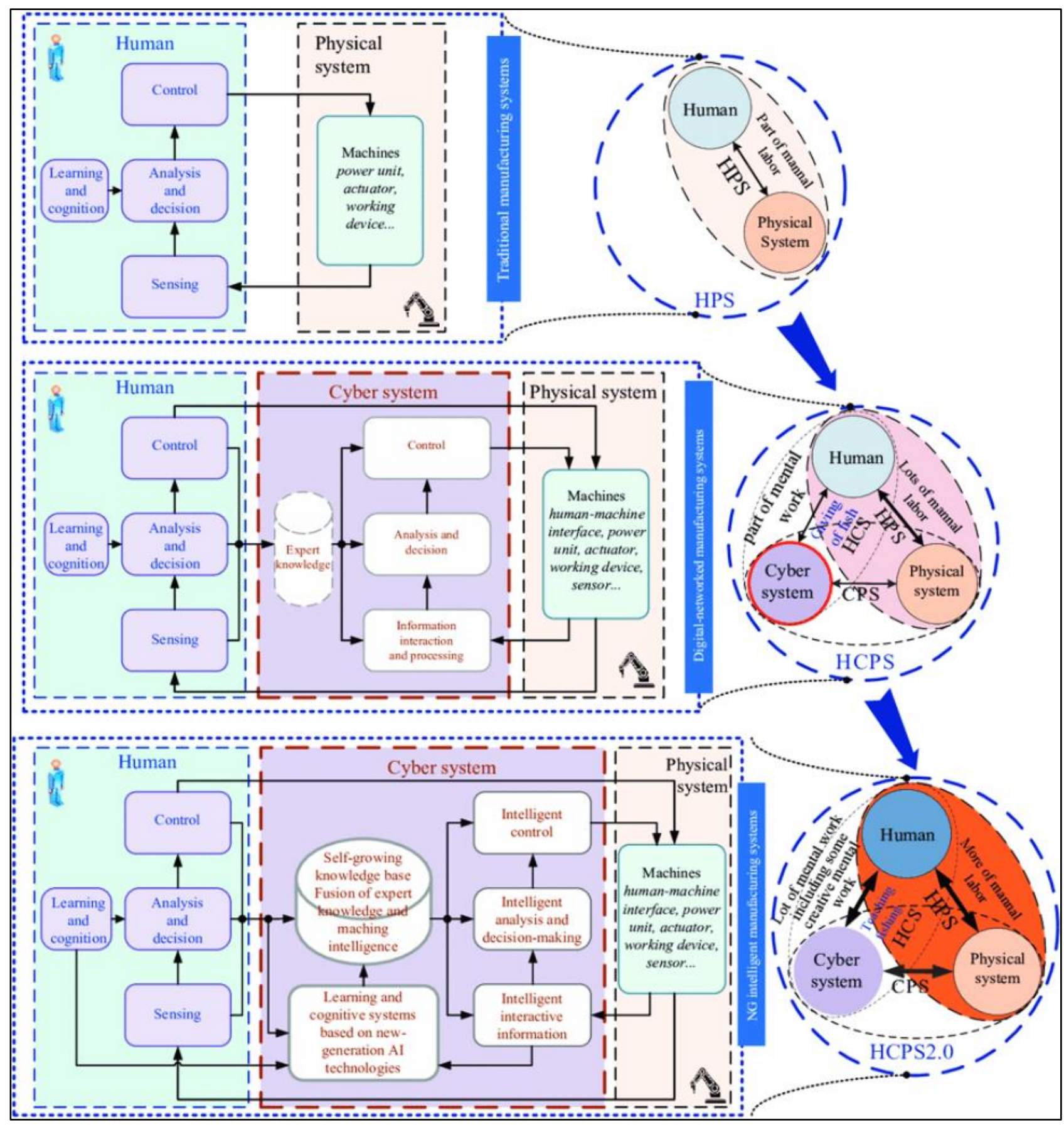

Fig. 2. Intelligent manufacturing: from human-physical systems (HPS) to humancyber-physical systems (HCPS) (Wang et al., 2018). 


\subsection{Product Design}

Artificial intelligence is also changing the way we design products. One method is to enter a detailed brief defined by designers and engineers as input into an AI algorithm (generative design).

The brief can include data describing restrictions and various parameters such as material types, available production methods, budget limitations and time constraints. The algorithm explores every possible configuration, until an optimal design solution is reached (Buchmeister \& Palcic, 2017). One of the major advantages of this approach is that an $\mathrm{AI}$ algorithm is completely objective.

\subsection{Digital Twins}

A digital twin is a virtual model of a process, product or service. The digital twin leverages the Internet of Things (IoT) but requires the skills of machine learning and AI. Digital twins are especially useful when working with equipment from a remote distance.

\subsection{Virtual Reality}

Virtual Reality will enable new tools that help to perform testing in the virtual world. It allows people, remotely located, to connect and jointly work on situations that require trouble shooting. Simulation and product-creation can help reduce the manufacturing time drastically.

\subsection{Automation}

Automation will help the manufacturing industry reach a high level of accuracy and productivity, a level that is even beyond human ability (Haskovic et al., 2018). It can even work in environments that are otherwise dangerous, tedious or complicated for humans. Robotics, which is expected in the future, will have capabilities like voice and image recognition that can be used to re-create complex human tasks.

\subsection{Quality}

Quality involves the use of AI algorithms to notify manufacturing teams of emerging production faults that are likely to cause product quality issues.

Machine-vision tools can find microscopic defects in products at resolutions well beyond human vision, using a machine-learning algorithm trained on remarkably small volumes of sample images. When integrated with a cloud-based data processing framework, defects are instantly flagged and a response is automatically coordinated (Xue et al., 2018).

\subsection{Smart Maintenance}

In manufacturing, ongoing maintenance of production line machinery and equipment represents a major expense, having a crucial impact on the bottom line of any assetreliant production operation. Therefore, predictive maintenance has become a musthave solution for manufacturers. Predictive maintenance uses advanced AI algorithms in the form of machine learning and artificial neural networks to formulate predictions regarding asset malfunction. This allows for drastic reductions in costly unplanned 
downtime, as well as for extending the Remaining Useful Life of production machines and equipment.

Predictive maintenance saves businesses valuable time and resources, including labour costs, while guaranteeing optimal manufacturing performance. With digital twins, sensors and advanced analytics embedded in manufacturing equipment this is possible. They enable predictive maintenance by responding to alerts and resolving machine issues.

\subsection{Other Possibilities}

Cloud-based machine learning is allowing manufacturers to streamline communication between their many branches. Data collected on one production line can be interpreted and shared with other branches to automate material provision, maintenance and other previously manual undertakings. AI in manufacturing is reaching a wider and wider level of adoption, and for good reason. McKinsey predicts that 'smart factories' will drive $\$ 37$ trillion in new value by 2025 (Puittinen, 2018).

AI facilitates to conquer many internal challenges that have been around in the industry: from expertise shortage to complexity in decision-making, issues related to integration, and overloaded information. Making use of AI in manufacturing plants enables businesses to completely transform their proceedings (Plant Automation, 2019):

- Robots are capable to work for 24/7 in the production line. Businesses can be witnessed to expand in terms of production capabilities and meet the high demand of customers worldwide.

- A step towards AI means less human resources have to carry out dangerous and overly laborious work. As robots replace humans and perform normal and risky activities, the number of workplace accidents will decrease all across.

- Although, bringing AI onto the manufacturing industry would necessitate a huge capital investment, the ROI is significantly high - businesses can enjoy considerably lower operating cost.

\section{Energy Sector}

In the energy sector, a lot excitement is around the implementation of intelligent networks that connect producers, consumers, and storage, and supply energy just in time when needed. AI is used to predict energy consumption peaks and help with realtime optimization of operations settings.

An energy- and resource-friendly production is an important key performance indicator for industrial companies to work economically and thus remain competitive. For this software systems are necessary for analysis, evaluation, diagnosis and planning. Thanks to intensive research efforts in the field of AI a number of AI based techniques such as machine learning, deep learning and artificial neural networks (ANN) have already been established in industry, business and society. Willenbacher et al. (2018) addressed the problem of energy- and resource efficiency in production processes of manufacturing companies. They present an approach to improve energyand resource efficiency by methods of AI. An integrated database of measures was 
designed to support sustainable production. The investigations were carried out prototypically using an ANN in combination with fuzzy logic and evolutionary algorithms (EA).

Thanks to increased energy use and requirements, we're going to need more power. Resources are growing scarcer despite the focus on climate change and sustainability, and there will be continued reliance on fossil fuels. This could potentially be mitigated by innovative recycling technologies, and using technology platforms to streamline processes and improve efficiency (Hall, 2017).

\section{Societal Impact}

It is unclear what implications AI will have on society now and in the long term. Sure, there is a significant impact, with positive and negative consequences, and value, collaboration, sharing responsibilities and ethics will play a vital role in any future sustainable development of AI in society.

Academic studies and books have variously examined the potential of intelligent machines to disrupt labour markets (Brinjolfsson \& McAfee, 2011; Ford, 2015), redefine social interaction and relations (Carr, 2014), and even detailed, serious-minded study of its potential threat to human existence (Bostrom, 2014).

The expansion of computing and machine intelligence is likely to affect healthcare, education, privacy and cybersecurity, and energy and environmental management. It will imply an education system shifting from a focus on mathematics and reading to a different set of personal and intellectual skills that facilitate working in tandem with intelligent machines (Brinjolfsson \& McAfee, 2014).

Other concerns lie in the field of digital ethics, which tries developing guidelines to make sure that autonomous agents comply with our moral and ethical standards. Data privacy will become even more important as we need to protect individuals from the growing desire from corporations and intelligence agencies for data as the most valuable resource for the development of more powerful algorithms. Widespread AI education and accessibility is crucial in order to prevent that AI will increase the global divide and lead to an unfair advantage in the hands of very few countries and organizations.

We are seeing population growing in some nations and shrinking in others, a growing middle class, consumer markets shifting from the west to the east and an ageing population with fewer people entering the manufacturing field.

Three major societal trends (Berry, 2019) are:

1) The value of personal data is increasing.

People have a right from forced disclosure. They have a right to privacy. Like many rights, we make choices, either collectively or individually, to relax that right. More people value their right from forced disclosure and adopt technologies that protect their personal data. The trend toward encryption and ad blocking are in part related to the reassessment of the value of their own data. More firms are able to augment the value of personal data they get by mixing it with additional data sources. For instance, your CV, by itself, has value. 
Information technology (IT) has become much better at generating new data, in particular from sensors embedded in wearable and connected devices. The value of personal data is increasing because it is more valuable to the people who own it, and to the organizations that lease the privilege to use it.

2) The demand for equity is increasing.

Equity is a strategy of enabling people to have an equal opportunity to succeed. It should not be confused with equality, which is a strategy for causing equal outcomes. This trend also applies to recommendation engines. Sometimes the biases that are inherent in society appear in the data that society produces. This has led to increased interest in fairness, accountability and transparency in machine learning and greater regulatory demand for the explainability of the decisions produced by a recommendation engine.

3) The sense of polarization is increasing.

For many reasons, people are more polarized. In spite of an increase in connectivity and wealth, our political and economic systems appear to be increasingly polarized too.

The three societal trends are fuelling new regulation. State regulation on data collection, processing and use is heterogeneous. For instance, under GDPR, data about ethnic origin, health, sexual orientation and political, philosophical and religious beliefs is prohibited.

In order for the society to benefit from AI, one way of reducing the negative impacts within the sustainability dimension is through aligning the values of all stakeholders during the design process of AI-enabled applications so that their goals and behaviours resemble the human values.

\subsection{Availability of Jobs}

Manufacturers will feel the challenges of a decreasing talent pool. There will not be enough skilled people to perform the jobs of the future. The available pool of workers will likely come from developing countries as we see greater percentages of the population earning post-secondary degrees in their more developed counterparts. An ever-increasing mobile workforce will continue to present challenges to employers and may lead to a global struggle for talent. Their wants and needs are very different to those of the generation before (Hall, 2017).

The present and coming wave of artificial intelligence will displace humans faster than we can adapt, through the acquisition of new skills and education. The robots are going to win the race. On the other hand, there are those who seek to emphasise that the introduction of technologies tends to lead to aggregate growth in employment, as the economy adjusts and demand is created in new sectors (Autor, 2015).

Since the end of 2018, there are more than 1.3 million industrial robots at work in factories all over the world (Kushmaro, 2018). In theory, as more and more jobs are taken over by robots, workers will be trained for more advanced positions in design, maintenance, and programming. In this interim phase, human-robot collaboration will have to be efficient and safe as more industrial robots enter the production floor alongside human workers. Automation will render obsolete as many as 800 million jobs worldwide by 2030 (Byrum, 2018). 
Aggregate employment remains stable, even as sectors are disrupted and replace by new ones. Suppose that the human want for new things (goods or services) is essentially unlimited. The desire for new products drives technological innovation. More technology leads to yet more new possibilities for products and services, entailing as yet unfathomed employment possibilities for workers. Expansion driven by intelligent machines, which produce like skilled workers but do not consume, would disrupt the process of labour absorption.

As AI takes over the manufacturing plant and automates boring and ordinary human tasks, workers will get to focus on complex and innovative tasks. Automation does substitute for labour, but it also complements labour and raises output in ways that lead to a higher demand for labour. The expansion in high-skill employment can be explained by the falling price of carrying out routine tasks by means of computers, which complements more abstract and creative services. In manufacturing, AI is more likely to change your job than eliminate it (Fig. 3). If it is true that workers are in a race against technology, the question is how long education can keep giving them an edge.

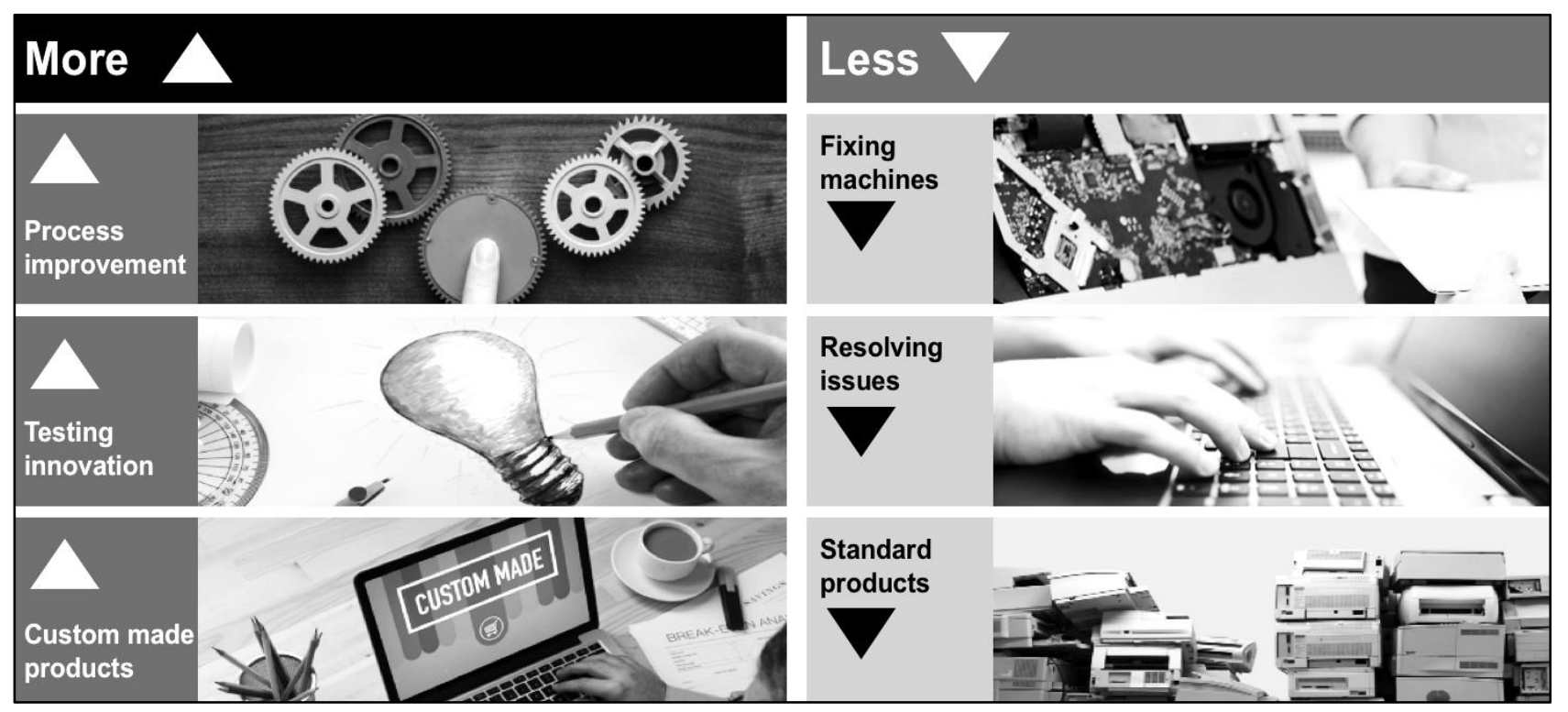

Fig. 3. AI changes manufacturing jobs.

Jobs with a high share of tasks involving judgement, creativity and persuasion, which are not easily quantified and codified, are less suitable for automation. Jobs requiring visual and language recognition, adaptability and in-person interactions, are also not susceptible to automation.

Automation changes the types of employment, with significant dislocation in some sectors, with job gains disproportionately going to high-skilled and low-skilled workers, coupled with a hollowing-out of routine middle-income jobs. Automation will continue to put downward pressure on the wages of the low skilled and is starting to impinge on the employment prospects of middle-skilled workers. By contrast, the potential returns to highly skilled and more adaptable workers are increasing.

Managerial, professional and technical occupations have benefited from computerization - the surge of technology into their workplaces has complemented the work of those engaged in abstract jobs, with less time on acquiring and calculation and 
more time on interpretation and application (Autor, 2015). Workers in these abstractintensive occupations have made wage gains due to:

- combination of complementarity of information technology with these occupations,

- growing demand for their services, and

- relatively scarce labour supply.

The same has not been true for workers in occupations that are intensive in manual skills, which are only weakly complimented by computerization, do not benefit from a rising demand, and where there is a relatively large labour pool. The dynamics of employment are also influenced by globalization and trade agreements. Given that capital is highly mobile, but labour is not, employment in tradable sectors can be eroded by unfavourable terms of trade.

The likelihood that a job will in the future be automated depends on:

- certain attributes of a job, such as whether it entails creativity or persuasion,

- the capability of technology, in other words the degree to which machines acquire or can mimic human intelligence, and

- social and cultural norms.

The future of automation is difficult to predict, as is society's willingness to guide and steer its adoption. Some of the issues that should be considered by policymakers could include:

- strengthening social protection systems,

- implementing education policies that foster the skills required for a flexible work force,

- policies that promote shifting the labour force from low to higher skilled jobs, with enhanced retraining and safety nets for workers affected by trade agreements, and

- policies that promote investment in $\mathrm{R} \& \mathrm{D}$, fostering innovation in developed countries and emulation in developing countries.

AI tools will provide a competitive advantage to the companies that use them, meaning operations research (OR) will be in more demand, too; the OR jobs would grow $27 \%$ over the next decade (U. S. Bureau of Labor Statistics, 2018).

With growing intelligence of robots, robots will soon replace the workforce in factories. Every stage can be closely monitored with the help of sensors and data can be shared with AI and analytics software. Increased output, defect detection and corrective action are much faster and the entire production cycle is much more efficient (Khanna, 2018).

In the AI future, jobs requiring human creativity and management expertise will enjoy the greatest job security. Those who understand how to collaborate with other humans while working with AI tools to enhance their organization's effectiveness will create maximum value. The power of AI makes optimization techniques more generalized and easier to use. The key to professional survival will be in understanding the big picture of business optimization. No particular outcome is guaranteed, of course.

Some fear that as AI improves, it will supplant workers, creating an ever-growing pool of unemployable humans who cannot compete economically with machines. This 
concern, while understandable, is unfounded. In fact, AI will be the greatest job engine the world has ever seen.

\section{AI under a Sustainability Analysis Perspective}

Using AI brings not only opportunities but also risks for negative impacts for sustainability. The sustainability dimensions are defined as follows (Khakurel et al., 2018):

- The individual dimension covers individual freedom and agency (the ability to act in an environment), human dignity, and fulfilment.

- The social dimension covers relationships between individuals and groups (trust, communication, and balance between conflicting interests).

- The economic dimension covers financial aspects and business value (capital growth and liquidity, investment questions, and financial operations).

- The technical dimension covers the ability to maintain and evolve artificial systems over time.

- The environmental dimension covers the use and stewardship of natural resources (waste production, energy consumption, balance of local ecosystems, climate changes).

Fig. 4 shows the sustainability analysis diagram of the AI field according to the five dimensions of sustainability.

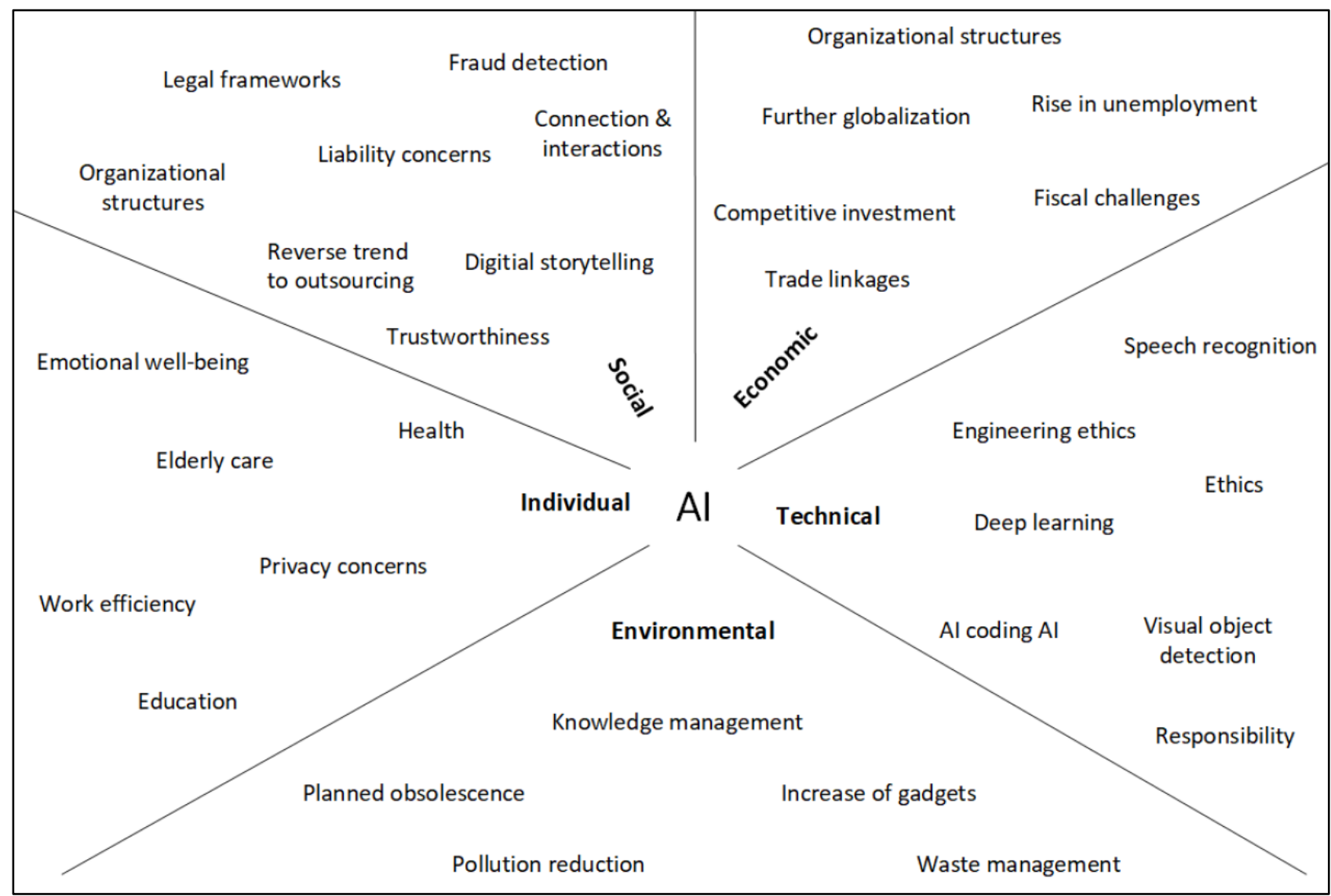

Fig. 4. Sustainability analysis diagram of the artificial intelligence field according to the five dimensions of sustainability (Khakurel et al., 2018). 


\subsection{Economic Dimension}

Governments of countries with advanced economies and large technology companies are investing in the implementation of AI to create a competitive advantage. Such investments give a competitive advantage at the national level for advanced economies; however, they also have negative impacts on the globalization of production and services. AI's capabilities will reduce or stop the outsourcing in the emerging market and bring services in-house. These will disrupt local businesses and the job markets of emerging economies, resulting in a rise in unemployment and a decrease in individuals' spending power. This will eventually affect the global economy. AI is already a major industry and can displace low-skilled workers.

\subsection{Technical Dimension}

Deep learning allows models that are composed of multiple processing layers to learn representations of data that have multiple levels of abstraction. This will lead to progress in AI being able to code AI (Simonite, 2018) causing disruption towards jobs in the IT industry. In terms of the positive impact, we can expect more capable systems that can take over tasks that are more complex. In terms of the negative impacts, we can perceive the necessity of stronger engineering ethics as more and more responsibilities are placed into the hands of the developers who engineer the systems upfront and hence must foresee many wanted and unwanted usage scenarios.

\subsection{Environmental Dimension}

AI may be useful in helping us take better care of the planet in terms of supporting waste and pollution management, but also, predictive systems can be used for earthquakes and weather forecasting to better recognize the likelihood of extreme event occurrences.

The adoption of autonomous vehicles could be a possible turning point for reducing greenhouse gas emissions through less fuel consumption (Iglinski \& Babiak, 2017).

AI can also have negative impact towards environmental dimension especially due to the contribution it makes towards further acceleration, and consumption of technological devices. The increased production and consumption of technological devices will have two adverse effects, namely planned obsolescence and depletion of natural resources.

\subsection{Individual Dimension}

We have become increasingly more productive in the last 50 years (Lightman, 2018). However, due to job requirements and inflation, individuals are working more than before. A person working more than normal working hours has a significantly higher risk of poor self-rated health and that this affects mental and emotional wellbeing.

AI-powered digital assistants, chatbots, analytical tools, and robots could help individuals in terms of working less hours, increase work efficiency, improve workers' physical well-being and reduce work-related injuries (Khakurel et al., 2018). 
The individual will have more interaction with machines. This will subsequently reduce the meaningfulness of the human-to-human interactions that we have with others, disconnecting us from the world around us, creating more social isolation and limiting us with digital emotions.

Additional questions raise on how much privacy individuals really have in the era of AI when data are collected intentionally or unknowingly.

\subsection{Social Dimension}

AI can take a minor role in assisting in communities, managing social media and automating routine tasks that are commonly outsourced. We can see benefits, as well as the dangers; there is the chance to strengthen communities, but also a requirement to develop legal frameworks around AI, and all of the strengths and weaknesses here come with the threat of turning over too much power to AI (Wisskirchen et al., 2017). A mistaken interpretation of a real-world event by an AI system could lead to serious conflicts. We live in a world of limited resources, including time, energy, money and the great transitions. In this context, nations, organizations compete to design AI enabled system to gain power and to have influence over others. All European Union members have signed a Declaration of Cooperation on AI to put forward the European approach to Artificial Intelligence based on three pillars (EU Commission, 2018):

- being at the forefront of technological developments and encouraging their uptake by the public and private sectors,

- preparing for socio-economic changes brought about by AI, and

- ensuring an appropriate ethical and legal framework.

\section{Conclusion}

This chapter discusses influence of intelligent manufacturing from the perspectives of the problems and challenges of the manufacturing industry, major opportunities and core technologies of the new round of industrial revolution, from current status to future trends.

In today's fast moving global markets, manufacturers need to respond quickly to changing demands and maximise new market opportunities. From all indications, we are in an era of significant convergence, where information technology, operational technology, and global megatrends are on a collision course. This will drive changes in how we do business and how we interact with customers and suppliers.

Today's students ought to pay close attention to AI trends. They would be best served by focusing on developing general skills that are highly adaptable, such as mathematical modelling, statistics and science. That way, they will be prepared to use increasingly powerful AI tools.

AI can and will make an impact in many different cases. The key to making AI contribute to a smarter, greener world is to take action now in order to visualise and direct how this technology could look like in 5 to 10 years. The outcomes of our investment in AI must be in line with a sustainable future and a better place for all of us. AI has become an innovative and revolutionary assistant in a wide range of applications and fields. 
Existing manufacturing systems and manufacturing levels can hardly meet the needs of value-added upgrades to high-end, personalized, intelligent products and services. New-generation intelligent manufacturing will bring revolutionary changes to the manufacturing sector, set the stage for a real fourth industrial revolution. The manufacturing sector is a perfect fit for the application of AI. Even though the Industry 4.0 revolution is still in its early stages, we are already witnessing significant benefits from AI. From the design process and production floor, to the supply chain and administration, AI is destined to change the way we manufacture products and process materials forever.

AI may be efficient at creating things, improving them, and making them cheaper. Nevertheless, there is no replacement for human ingenuity in dealing with the unanticipated changes in tastes and demands or in deciding whether to make things at all. We have to significantly shift our thinking towards a transformation mind-set for a joint sustainable vision of the future.

We analyse the rapid development of core technologies in the new AI era, which is triggering a great change in the models, means, and ecosystems of the manufacturing industry. Our findings show that new technologies are urgently needed to resolve the key problems in knowledge generation, efficient utilization, and large-scale application in the manufacturing processes and further realize the capability and value in the entire manufacturing system. Of course, broader social influence should not be ignored too. The key technology of new-generation intelligent manufacturing systems, that is, newgeneration AI technology, provides the systems with the ability to learn and discover relevant knowledge and mechanisms and achieve human-machine collaboration through big data intelligence, human-machine hybrid enhancement intelligence, crowd intelligence, and other means.

The wide application of intelligent manufacturing will push the new round of the industrial revolution to its culmination, bringing revolutionary changes to the manufacturing industry and human society in the direction of people-oriented, intelligent, harmonious, green, and safe development.

In our future research, we will focus on the introduction requirements of $\mathrm{AI}$ in key areas of production and at essential technologies in connection with the appropriate support of production management, likewise supported with AI.

\section{Acknowledgement}

The authors acknowledge the financial support from the Slovenian Research Agency (research core funding No. P2-0190).

\section{References}

Autor, D. (2015). Why are there still so many jobs? The history and future of workplace automation. Journal of Economic Perspectives, Vol. 29, No. 3, pp. 3-30, ISSN 08953309

Berry, C. (2019). Societal trends create new challenges for data scientists. Analytics, Jan/Feb Issue, in Forum (published online), doi:10.1287/LYTX.2019.01.07 
Bostrom, N. (2014). Superintelligence: Paths, Dangers, Strategies, Oxford University Press, ISBN 978-0-19-873983-8, New York

Brynjolfsson, E.; McAfee, A. (2011). Race Against the Machine, Digital Frontier Press, eISBN 978-0-9847251-0-6, Lexington

Brynjolfsson, E.; McAfee, A. (2014). The Second Machine Age, W. W. Norton \& Co., ISBN 978-0-393-23935-5, New York

Buchmeister, B. \& Palcic, I. (2017). Product development using an intelligent supporting system, In: DAAAM International Scientific Book 2017, Katalinic, B. (Ed.), pp. 43-54, DAAAM International, ISBN 978-3-902734-12-9, Vienna

Byrum, J. (2018). Preparing for an AI future, ORMS Today, Vol. 45, No. 6, pp. 24-26, ISSN 1085-1038

Carr, N. (2014). The Glass Cage: Automation and Us, W. W. Norton \& Co., ISBN 9780-393-24076-4, New York

EU Commission (2018). Digital single market EU member states sign up to cooperate on artificial intelligence. Available from: https://ec.europa.eu/digital-singlemarket/en/news/eu-member-states-sign-cooperate-artificialintelligence. Accessed on 2018-11-18

Forbes. Insights Team (2018). How AI builds a better manufacturing process. Available from: https://www.forbes.com/sites/insights-intelai/. Accessed on 2019-0306

Ford, M. (2015). Rise of the Robots: Technology and the Threat of a Jobless Future, Basic Books, ISBN 978-0-465-05999-7, New York

Hall, S. (2017). Manufacturing Global: Megatrends pushing manufacturers towards Industry 4.0, Available from: https://www.manufacturingglobal.com/leanmanufacturing/. Accessed on 2019-03-05

Haskovic, D.; Katalinic, B.; Zec, I. \& Kukushkin, I. (2018). Contribution of intelligent adviser module proposals in bionic assembly system, Proceedings of the $29^{\text {th }}$ DAAAM International Symposium, Katalinic, B. (Ed.), pp. 1299-1305, ISBN 978-3-902734-204, Zadar, Croatia, October 2018, DAAAM International, Vienna

Huang, M.-H. \& Rust, R. T. (2018). Artificial intelligence in service. Journal of Service Research, Vol. 21, No. 2, pp. 155-172, ISSN 1094-6705

Iglinski, H. \& Babiak, M. (2017). Analysis of the potential of autonomous vehicles in reducing the emissions of greenhouse gases in road transport. Procedia Engineering, Vol. 192, pp. 353-358, ISSN 1877-7058

Khakurel, J.; Melkas, H. \& Porras, J. (2018). Tapping into the wearable device revolution in the work environment: A systematic review. Information Technology \& People, Vol. 31, No. 3, pp. 791-818, ISSN 0959-3845

Khakurel, J.; Penzenstadler, B.; Porras, J.; Knutas, A. \& Zhang, W.-L. (2018). The rise of artificial intelligence under the lens of sustainability. Technologies, Vol. 6, No. 4, Paper 100, 18 pages, e-ISSN 2227-7080

Khanna, R. (2018). ISHIR: How is artificial intelligence changing the manufacturing industry in 2018? Available from: https://www.ishir.com/blog/4654/artificialintelligence-in-manufacturing-industry.htm. Accessed on 201903-06

Kushmaro, P. (2018). CIO: 5 ways industrial AI is revolutionizing manufacturing. Available from: https://www.cio.com/article/3309058/. Accessed on 2019-03-07 
Lightman, A. (2018). In Praise of Wasting Time, Simon and Schuster, ISBN 978-15011-5436-2, New York

Müller, V. C. (2014). Risks of general artificial intelligence. Journal of Experimental \& Theoretical Artificial Intelligence, Vol. 26, No. 3, pp. 297-301, ISSN 0952-813X Pavaloiu, A. \& Kose, U. (2017). Ethical artificial intelligence - An open question. Journal of Multidisciplinary Developments, Vol. 2, No. 2, pp. 15-27, e-ISSN: 25646095

Plant Automation (2019). Technology: The future of artificial intelligence in manufacturing industries, Available from: https://www.plantautomationtechnology.com/articles. Accessed on 2019-03-10

Puittinen, M. (2018). Nordcloud: 10 examples of AI in manufacturing to inspire your smart factory. Available from: https://nordcloud.com/10-examples-of-ai-inmanufacturing-to-inspire-your-smart-factory/. Accessed on 2019-03-15

Silva, L. (2018). Cognifide: How can we use AI to drive the sustainability agenda? Available from: https://www.cognifide.com/our-blogs/. Accessed on 2019-03-20

Simonite, T. (2018). AI software learns to make AI software. Available from: https://www.technologyreview.com/s/603381/ai-software-learns-to-make-ai-

software/. Accessed on 2018-09-20

Tegmark, M. (2017). Life 3.0: Being Human in the Age of Artificial Intelligence, A. A. Knopf, ISBN 978-1-101-97031-7, New York

U. S. Bureau of Labor Statistics, Office of Occupational Statistics and Employment Projections (2018). Occupational Outlook Handbook (Operations Research Analysts). Available from: https://www.bls.gov/ooh/math/operations-research-analysts.htm. Accessed on 2019-04-13

Wang, B.; Zang, J.; Qu, X.; Dong, J. \& Zhou, Y. (2018). Research on new-generation intelligent manufacturing based on human-cyber-physical systems. Strategic Study of Chinese Academy of Engineering, Vol. 20, No. 4, pp. 29-34, ISSN 1009-1742

Willenbacher, M.; Kunisch, C. \& Wohlgemuth, V. (2018). Application of methods of artificial intelligence for sustainable production of manufacturing companies, In: From Science to Society, Otjacques, B.; Hitzelberger, P.; Naumann, S. \& Wohlgemuth, V. (Eds.), pp. 225-236, Springer, ISBN 978-3-319-65686-1, Cham

Wisskirchen, G.; Biacabe, B. T.; Bormann, U.; Muntz, A.; Niehaus, G.; Soler, G. J. \& von Brauchitsch, B. (2017). Artificial intelligence and robotics and their impact on the workplace, IBA Global Employment Institute, London

Xue, P.; Jiang, C. H.; Wei, W. \& Lin, J. (2018). Optimization of the intelligent workshop control based on the improved group leadership optimization algorithm. International Journal of Simulation Modelling, Vol. 17, No. 4, pp. 690-701, ISSN $1726-4529$

Zavalishina, J. (2017). Manufacturing Global: AI and sustainability: go green and get paid for it. Available from: https://www.manufacturingglobal.com/technology/. Accessed on 2019-03-11

Zhou, J.; Li, P.; Zhou, Y.; Wang, B.; Zang, J. \& Meng, L. (2018). Toward newgeneration intelligent manufacturing. Engineering, Vol. 4, No. 1, pp. 11-20, ISSN 2095-8099 